\title{
Navafenterol (AZD8871) in patients with mild asthma: a randomised placebo- controlled phase I study evaluating the safety, tolerability, pharmacokinetics, and pharmacodynamics of single ascending doses of this novel inhaled long-acting dual-pharmacology bronchodilator
}

Eulalia Jimenez ${ }^{1 *}$, Carol Astbury ${ }^{2}$, Muna Albayaty $^{3}$, Ulrika Wählby-Hamrén $^{4}$, Beatriz Seoane ${ }^{5}$, Cristina Villarroel $^{6}$, Helena Pujol ${ }^{2}$, Maria Jesus Bermejo ${ }^{7}$, Ajay Aggarwal ${ }^{2}$ and loannis Psallidas ${ }^{8}$

\begin{abstract}
Background: Navafenterol (AZD8871) is an inhaled long-acting dual-pharmacology muscarinic antagonist/ $\beta_{2^{-}}$ adrenoceptor agonist (MABA) in development for the treatment of obstructive airways diseases. The safety, tolerability, pharmacodynamics, and pharmacokinetics of navafenterol were investigated in patients with mild asthma.

Methods: This was a randomised, single-blind, placebo-controlled, single-ascending-dose study. Patients were randomly assigned to one of two cohorts which evaluated escalating doses of navafenterol (50-2100 $\mu \mathrm{g})$ in an alternating manner over three treatment periods. The primary pharmacodynamic endpoint was the change from predose baseline in trough forced expiratory volume in $1 \mathrm{~s}\left(\mathrm{FEV}_{1}\right)$ for each treatment period.

Results: Sixteen patients were randomised; 15 completed treatment. Data from all 16 patients were analysed. The maximum tolerated dose was not identified, and all doses of navafenterol were well tolerated. The most frequently reported treatmentemergent adverse events (TEAEs) were headache $(n=10,62.5 \%)$ and nasopharyngitis $(n=7,43.8 \%)$. No TEAEs were serious, fatal, or led to discontinuation, and no dose dependency was identified. Navafenterol demonstrated a dose-ordered bronchodilatory response with a rapid onset of action (within 5 min post-dose). Doses $\geq 200 \mu \mathrm{g}$ resulted in improvements in trough FEV ${ }_{1}$ (mean change from baseline range $0.186-0.463 \mathrm{~L}$ ) with sustained bronchodilation for $24-36 \mathrm{~h}$. Plasma concentrations increased in a doseproportional manner, peaking $\sim 1 \mathrm{~h}$ post-dose, with a derived terminal elimination half-life of 15.96-23.10 $\mathrm{h}$.
\end{abstract}

Conclusions: In this study navafenterol was generally well tolerated with a rapid onset of action which was sustained over $36 \mathrm{~h}$. (Continued on next page)

\footnotetext{
* Correspondence: lali.jimenez@astrazeneca.com

${ }^{1}$ Clinical Pharmacology and Quantitative Pharmacology, Clinical Pharmacology \& Safety Sciences, R\&D, AstraZeneca, 08020 Barcelona, Spain Full list of author information is available at the end of the article
}

(c) The Author(s). 2020 Open Access This article is licensed under a Creative Commons Attribution 4.0 International License, which permits use, sharing, adaptation, distribution and reproduction in any medium or format, as long as you give appropriate credit to the original author(s) and the source, provide a link to the Creative Commons licence, and indicate if changes were made. The images or other third party material in this article are included in the article's Creative Commons. licence, unless indicated otherwise in a credit line to the material. If material is not included in the article's Creative Commons licence and your intended use is not permitted by statutory regulation or exceeds the permitted use, you will need to obtain permission directly from the copyright holder. To view a copy of this licence, visit http://creativecommons.org/licenses/by/4.0/. The Creative Commons Public Domain Dedication waiver (http://creativecommons.org/publicdomain/zero/1.0/) applies to the data made available in this article, unless otherwise stated in a credit line to the data. 
(Continued from previous page)

Trial registration: ClinicalTrials.gov; No.: NCT02573155

Keywords: Bronchodilator, Asthma, MABA, dual-pharmacology muscarinic receptor antagonist $\beta_{2}$-adrenoceptor agonist, Safety, Pharmacokinetics

\section{Background}

Inhaled bronchodilators are used widely in the symptomatic management of asthma [1]. The long-acting muscarinic antagonist (LAMA) bronchodilator tiotropium is recommended as an add-on to dual therapy with an inhaled corticosteroid (ICS) and a long-acting $\beta_{2}$ receptor agonist (LABA) bronchodilator for the treatment of patients with severe asthma that is not well controlled with ICS/LABA therapy [1]. Modest improvements in lung function [2-4] and a decreased risk of severe exacerbations requiring oral corticosteroids have been reported with this combination of therapies $[2,3]$.

Compared with LAMA/LABA combinations, a single molecule with dual muscarinic antagonist and $\beta_{2}$ agonist (MABA) properties may be more readily co-formulated with ICS and/or novel anti-inflammatory agents $[5,6]$, potentially simplifying dosing regimens and improving patient compliance [5, 7-9]. Additionally, the use of a single bifunctional molecule allows the delivery of a fixed drug ratio into every region of the lung and a uniform ratio of activities at the cellular level, and offers the potential for additive or synergistic bronchodilation vs bronchodilators with a single mechanism of action $[5,10,11]$.

Navafenterol (AZD8871) is a novel MABA currently being developed as an inhaled long-acting bronchodilator (e-Fig. 1). Through its dual pharmacological activity, it is anticipated that navafenterol would offer greater efficacy than single-mechanism LABAs or LAMAs, and similar or potentially greater efficacy than free- or fixed-dose combination therapies, with an equivalent or superior safety and tolerability profile. This first-in-human phase I study (NCT02573155) was conducted in two parts: a singleascending-dose study in male patients with mild asthma (Part 1) and a 5-way cross-over, single-dose study in patients with moderate to severe chronic obstructive pulmonary disease (COPD; Part 2). In Part 2, single doses of navafenterol at 400 and $1800 \mu \mathrm{g}$ were well tolerated and produced rapid and sustained bronchodilation over $36 \mathrm{~h}$ [12]. Here, we report data from Part 1 of the study, which was designed to evaluate the safety, tolerability, pharmacokinetics (PK), and pharmacodynamics (PD) of single doses of navafenterol in patients with mild asthma.

\section{Methods}

\section{Study design and treatment}

This was a randomised, single-blind, placebo-controlled study conducted at a single site (PAREXEL Early Phase
Clinical Unit, Northwick Park Hospital, Harrow, UK). The primary objectives were to assess the safety, tolerability, and PD of single doses of navafenterol, and the secondary objective was to assess the PK of navafenterol and its metabolite after single doses of navafenterol. The study protocol and consent form were reviewed and approved by an Independent Ethics Committee (NRES Committee - Cambridgeshire and Hertfordshire, Health Research Authority, Nottingham, UK; Reference No 15/EE/0329) and the study was performed in accordance with the Declaration of Helsinki, the International Conference on Harmonisation/Good Clinical Practice and the AstraZeneca bioethics policy. All patients provided written informed consent before taking part in the study.

Following a screening evaluation and run-in period of 14 to 28 days, patients were withdrawn from their usual non-ICS asthma therapies. Patients receiving ICS monotherapy were maintained on their usual ICS therapy, and patients receiving fixed-dose combinations of ICS/LABA were permitted to switch to the same ICS but in a monotherapy formulation. Patients were randomly assigned to one of two cohorts: each cohort received one of six navafenterol dose levels per treatment period (Fig. 1). Doses were sequentially escalated over the three treatment periods, separated by a minimum washout period of 14 days. During each treatment period, patients received either navafenterol or placebo (both delivered using a variant of the Genuair ${ }^{\text {rm }} /$ Pressair $^{\circ 1}$ dry-powder inhaler, adapted internally to deliver a single dose of inhalation powder), at the same time each morning. Salbutamol was permitted as reliever medication when required for the duration of the study. A follow-up visit was performed 7 $( \pm 2)$ days after the last treatment period or after discontinuation, and patients were contacted by telephone 14 ( \pm 2) days after the last treatment period to record any adverse events (AEs; defined as undesirable medical conditions which developed or deteriorated at any time during the study, irrespective of causality). Treatment-emergent AEs (TEAEs) were defined as AEs that developed (or increased in severity) after the first administration of the study drug and within 14 days of the last administration of the study drug.

\footnotetext{
${ }^{1}$ Registered trademarks of the AstraZeneca group of companies; for use within the USA as Pressair ${ }^{\circ}$ and Genuair $^{\mathrm{Tw}}$ within all other licensed territories.
} 


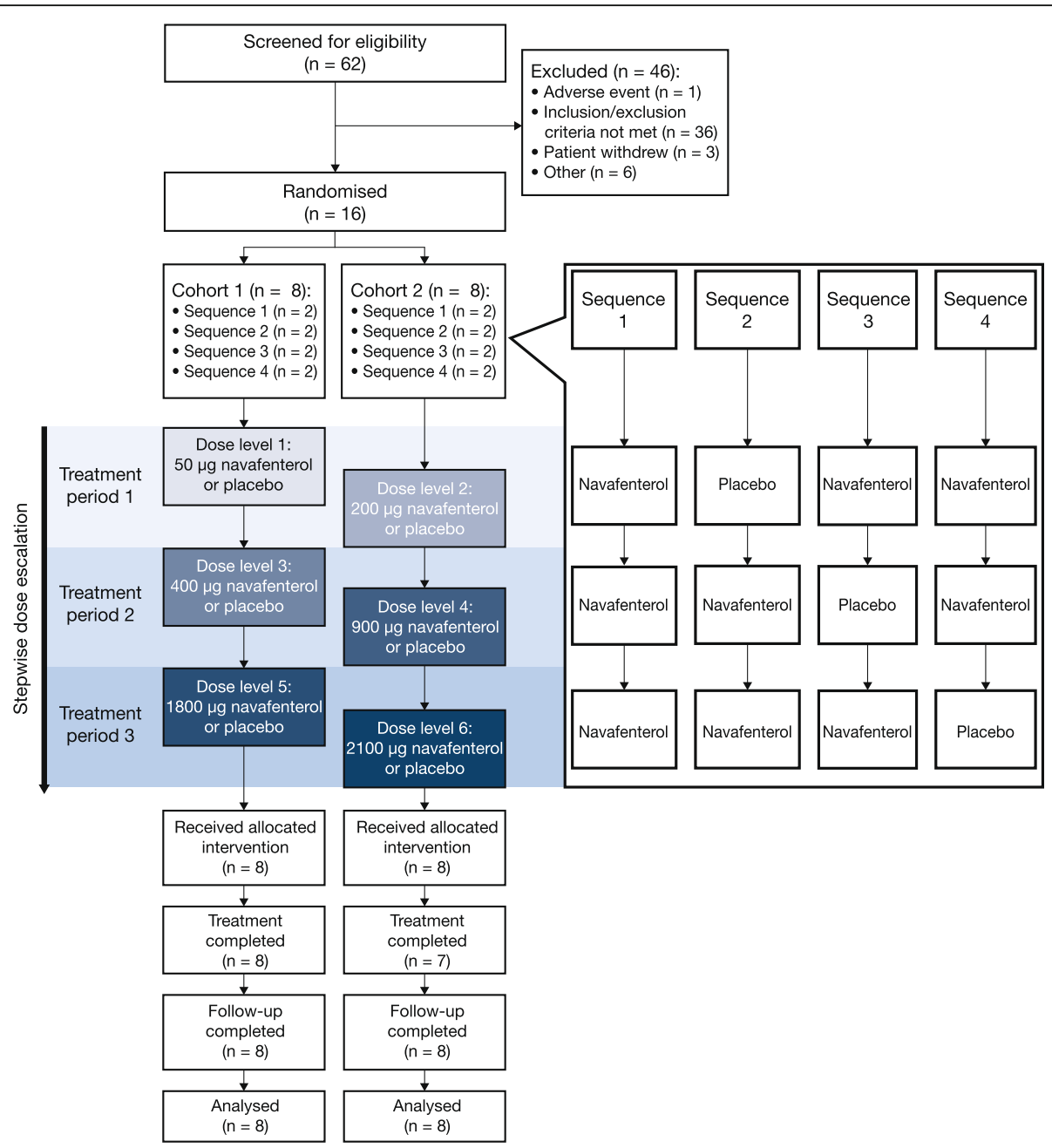

Fig. 1 Patient disposition and flow

\section{Participants}

Eligible patients were males aged $18-70$ years with a body mass index of $18-32 \mathrm{~kg} / \mathrm{m}^{2}$ and a clinical diagnosis of asthma (according to the Global Initiative for Asthma guidelines) for at least 6 months prior to screening. For inclusion, patients were required to: be non-smokers with a smoking history of $\leq 10$ pack-years; have a forced expiratory volume in $1 \mathrm{~s}\left(\mathrm{FEV}_{1}\right)$ value of $\geq 70 \%$ of the predicted normal at screening; and have $\mathrm{FEV}_{1}$ reversibility of $\geq 12 \%$ and an absolute increase of $\geq 200 \mathrm{~mL}$ vs baseline within $30 \mathrm{~min}$ after inhalation of $400 \mu \mathrm{g}$ of salbutamol. Patients were otherwise healthy, as determined by medical history, physical examination, and 12lead digital electrocardiogram (ECG) findings. Key exclusion criteria included a current diagnosis of COPD or other clinically significant unstable disease, and increased maintenance treatments for asthma or an asthma exacerbation requiring hospitalisation within the 6 weeks prior to screening or randomisation.

\section{Assessments}

\section{Safety and tolerability}

AEs, coded using the Medical Dictionary for Regulatory Activities version 18.1, were collected at each visit from consent until the telephone follow-up. Other safety assessments included physical examinations, vital signs (blood pressure and body temperature), clinical laboratory tests (chemistry; haematology; urinalysis; coagulation; and blood potassium and glucose measured using i-STAT), 12-lead digital ECG, and telemetry. For the timing of these assessments and the safety stopping criteria see e-Appendix 1 and e-Table 1.

\section{Pharmacodynamics}

The primary PD endpoint was the change from baseline (measured prior to the administration of study drug on day 1) in trough $\mathrm{FEV}_{1}$ (mean of two values measured at 23 and $24 \mathrm{~h}$ after the administration of study drug on day 1) for each treatment period. Key secondary 
endpoints included: the change from baseline in trough forced vital capacity, normalised $\mathrm{FEV}_{1}$ area under the curve from 0 to $6\left(\mathrm{AUC}_{0-6}\right), 0-12\left(\mathrm{AUC}_{0-12}\right), 12-24$ $\left(\mathrm{AUC}_{12-24}\right)$, and $0-24\left(\mathrm{AUC}_{0-24}\right) \mathrm{h}$ post-dose, and $\mathrm{FEV}_{1}$ at each scheduled timepoint on day 1 and day 2; and peak $\mathrm{FEV}_{1}$ on day 1 . For the timing of these assessments see e-Appendix 1.

\section{Pharmacokinetics}

The PK of navafenterol and its metabolite LAS191861 were assessed in plasma and urine. The plasma PK parameters assessed included the maximum plasma concentration $\left(\mathrm{C}_{\max }\right)$, time to reach $\mathrm{C}_{\max }\left(\mathrm{t}_{\max }\right)$, concentration-time $\mathrm{AUC}_{0-24}$, area under the concentration-time curve from time zero extrapolated to infinity $\left(\mathrm{AUC}_{0-\infty}\right)$, and terminal elimination half-life $\left(t_{1 / 2 \lambda}\right)$. Renal clearance and the fraction of the dose excreted unchanged into urine from 0 to $36 \mathrm{~h}$ $\left(\mathrm{fe}_{0-36 \mathrm{~h}}\right)$ were also assessed. For details of the sampling schedule and parameter assessments see e-Appendix 1.

\section{Statistical analysis}

Due to the exploratory nature of this trial, there was no formal sample size calculation. It was considered that a sample size of 16 patients would be sufficient to meet the objectives of the study. SAS version 9.2 or later (SAS Institute, Inc., Cary, NC) was used for all analyses.

Safety outcomes were analysed descriptively in the safety population (all randomised patients who received at least one dose of study medication). Analyses of PD were performed on the per protocol population; defined as all randomised patients who met the inclusion/exclusion criteria, completed at least one treatment period, and had no major protocol deviations. PK parameters were analysed descriptively in the PK population (all randomised patients with evaluable PK parameters who received at least one dose of study medication in any treatment period). Additional information regarding the statistical analyses can be found in e-Appendix 1 .

\section{Results}

\section{Participants}

The first patient was enrolled on October 30, 2015 and the last patient completed the study on March 24, 2016. Of the 62 patients screened for eligibility, 16 were randomised to treatment (Fig. 1). Fifteen patients (93.8\%) completed all scheduled treatments and the study. One patient was withdrawn before receiving navafenterol $2100 \mu \mathrm{g}$ during treatment period 3 after receiving treatment with amoxicillin and ibuprofen for pharyngitis. However, all randomised patients completed follow-up and were included in the safety, per protocol and PK populations. All patients showed reversibility at screening (Table 1).
Table 1 Patient Demographics and Baseline Characteristics (Safety Population)

\begin{tabular}{|c|c|}
\hline Baseline characteristic & Total population $(N=16)$ \\
\hline Age, years & $39.0(11.8)$ \\
\hline Male, n (\%) & $16(100)$ \\
\hline \multicolumn{2}{|l|}{ Race, n (\%) } \\
\hline Asian & $1(6.3)$ \\
\hline Black or African American & $1(6.3)$ \\
\hline White & $14(87.5)$ \\
\hline Weight, kg & $82.5(15.6)$ \\
\hline Height, cm & $174.9(7.9)$ \\
\hline Body mass index, $\mathrm{kg} / \mathrm{m}^{2}$ & $26.8(3.5)$ \\
\hline \multicolumn{2}{|l|}{ Smoking status, n (\%) } \\
\hline Former & $1(6.3)$ \\
\hline Never & $15(93.8)$ \\
\hline \multicolumn{2}{|c|}{ Asthma severity per GINA 2006 stages, n (\%) } \\
\hline Category $\mathrm{l}^{\mathrm{a}}$ & $8(50.0)$ \\
\hline Category $\|^{\mathrm{b}}$ & $8(50.0)$ \\
\hline Duration of asthma, years & $25.9(11.5)$ \\
\hline Prebronchodilator \% predicted $\mathrm{FEV}_{1}$ & $80.8(9.3)$ \\
\hline Bronchial reversibility, \% & $20.2(7.9)$ \\
\hline Prior medication ${ }^{\complement}$ for asthma, $\mathrm{n}(\%)$ & $1(6.3)$ \\
\hline
\end{tabular}

FEV ${ }_{1}$ forced expiratory volume in $1 \mathrm{~s}$, GINA Global Initiative for Asthma Data are mean (standard deviation) unless otherwise specified ${ }^{\mathrm{a}} \mathrm{FEV}_{1} \geq 80 \%$ of predicted value (mild persistent)

${ }^{\mathrm{b}} \mathrm{FEV}_{1} \geq 60 \%$ of predicted value and $<80 \%$ of predicted value ${ }^{c}$ Within 15 days prior to providing informed consent until the first administration of study medication

\section{Safety and tolerability}

After reviewing emerging data from each preceding dose level, as per protocol, the planned dose escalations for dose levels 2-6 $(100 \mu \mathrm{g}, 300 \mu \mathrm{g}, 600 \mu \mathrm{g}, 1200 \mu \mathrm{g}$, and $1800 \mu \mathrm{g})$ were increased to $200 \mu \mathrm{g}, 400 \mu \mathrm{g}, 900 \mu \mathrm{g}$, $1800 \mu \mathrm{g}$, and $2100 \mu \mathrm{g}$. The maximum tolerated dose was not identified in this study. Safety stopping criteria were not met and the predefined human exposure limit (determined from non-clinical toxicology investigations) was not reached following dose escalation to $2100 \mu \mathrm{g}$.

Overall, 14 (87.5\%) patients reported $\geq 1$ TEAE and 4 (25.0\%) patients reported treatment-related TEAEs. The most frequently reported TEAEs were headache $(n=10$, $62.5 \%)$ and nasopharyngitis $(n=7,43.8 \%$; Table 2$)$, and treatment-related TEAEs included headache $(n=3$, $18.8 \%)$, dizziness $(n=1,6.3 \%)$, and cough $(n=1 ; 6.3 \%)$. The incidence of TEAEs and treatment-related TEAEs was similar across treatment groups and dose levels, and all TEAEs were considered to be of mild or moderate intensity; none were severe, serious, fatal, or led to discontinuation. Furthermore, no TEAEs were related to laboratory findings. 
Table 2 Summary of TEAEs by Treatment and Dose (Safety Population)

\begin{tabular}{|c|c|c|c|c|c|c|c|c|}
\hline & Placebo & $\begin{array}{l}\text { navafenterol } \\
50 \mu \mathrm{g}\end{array}$ & $\begin{array}{l}\text { navafenterol } \\
200 \mu \mathrm{g}\end{array}$ & $\begin{array}{l}\text { navafenterol } \\
400 \mu \mathrm{g}\end{array}$ & $\begin{array}{l}\text { navafenterol } \\
900 \mu \mathrm{g}\end{array}$ & $\begin{array}{l}\text { navafenterol } \\
1800 \mu \mathrm{g}\end{array}$ & $\begin{array}{l}\text { navafenterol } \\
2100 \mu \mathrm{g}\end{array}$ & Overall \\
\hline N & 12 & 6 & 6 & 6 & 6 & 6 & 5 & 16 \\
\hline Any TEAE, n (\%) & $7(58.3)$ & $5(83.3)$ & $5(83.3)$ & $3(50.0)$ & $3(50.0)$ & $3(50.0)$ & $2(40.0)$ & $\begin{array}{l}14 \\
(87.5)\end{array}$ \\
\hline \multicolumn{9}{|c|}{ Most common TEAEs, n (\%) } \\
\hline Headache & $3(25.0)$ & $3(50.0)$ & $1(16.7)$ & $2(33.3)$ & $2(33.3)$ & $1(16.7)$ & 0 & $\begin{array}{l}10 \\
(62.5)\end{array}$ \\
\hline Nasopharyngitis & $1(8.3)$ & $3(50.0)$ & $1(16.7)$ & 0 & 0 & 0 & $2(40.0)$ & $\begin{array}{l}7 \\
(43.8)\end{array}$ \\
\hline $\begin{array}{l}\text { Chest } \\
\text { discomfort }\end{array}$ & $1(8.3)$ & $1(16.7)$ & $1(16.7)$ & 0 & 0 & 0 & 0 & $\begin{array}{l}3 \\
(18.8)\end{array}$ \\
\hline Skin irritation & 0 & $1(16.7)$ & $1(16.7)$ & 0 & 0 & $1(16.7)$ & 0 & $\begin{array}{l}3 \\
(18.8)\end{array}$ \\
\hline Wheezing & $1(8.3)$ & $1(16.7)$ & $1(16.7)$ & 0 & 0 & 0 & 0 & $\begin{array}{l}3 \\
(18.8)\end{array}$ \\
\hline Cough & 0 & $1(16.7)$ & 0 & 0 & $1(16.7)$ & 0 & 0 & $\begin{array}{l}2 \\
(12.5)\end{array}$ \\
\hline Dizziness & $1(8.3)$ & 0 & $1(16.7)$ & 0 & 0 & 0 & 0 & $\begin{array}{l}2 \\
(12.5)\end{array}$ \\
\hline Feeling hot & 0 & $1(16.7)$ & 0 & 0 & 0 & 0 & $1(20.0)$ & $\begin{array}{l}2 \\
(12.5)\end{array}$ \\
\hline Nausea & 0 & $1(16.7)$ & 0 & 0 & $1(16.7)$ & 0 & 0 & $\begin{array}{l}2 \\
(12.5)\end{array}$ \\
\hline
\end{tabular}

TEAE treatment-emergent adverse event

Adverse events were coded using Medical Dictionary for Regulatory Activities version 18.1

${ }^{a}$ Most common TEAEs reported by $\geq 2$ patients overall

There were no clinically significant changes in clinical laboratory parameters, vital signs, or ECGs. Small increases in heart rate and changes from baseline in mean QT interval corrected for heart rate using the Fridericia formula (QTcF) were observed, and were comparable across all treatment groups and dose levels (Fig. 2). However, mean QTcF values remained within the reference ranges for all doses at all timepoints. Small changes in iSTAT mean glucose and potassium values were observed for patients receiving placebo or navafenterol, but there was no observed pattern for the changes (e-Fig. 2).

\section{Pharmacodynamics}

The mean change from baseline in trough $\mathrm{FEV}_{1}$ (primary PD endpoint) increased with higher doses of navafenterol, demonstrating a dose-ordered bronchodilatory response (Fig. 3). Improvements, ranging from 0.186 to $0.463 \mathrm{~L}$ vs baseline, were observed with navafenterol doses $\geq 200 \mu \mathrm{g}$. Based on the results of an exploratory analysis of covariance, the improvements in the least squares mean change from baseline in trough $\mathrm{FEV}_{1}$ were statistically superior for navafenterol vs placebo at doses of $400 \mu \mathrm{g}(0.301 \mathrm{~L} ; 95 \%$ confidence interval [CI] 0.195, 0.406), $900 \mu \mathrm{g}(0.284 \mathrm{~L} ; 95 \%$ CI $0.176,0.391), 1800 \mu \mathrm{g}$ $(0.389 \mathrm{~L} ; 95 \% \mathrm{CI} 0.134,0.643)$, and $2100 \mu \mathrm{g}(0.414 \mathrm{~L} ; 95 \%$ CI 0.154, 0.673).
Administration of navafenterol resulted in a rapid onset of action, with all doses numerically increasing $\mathrm{FEV}_{1}$ vs baseline at both 5 and $15 \mathrm{~min}$ post-dose (e-Fig. 3). Bronchodilation was also sustained, with all doses $\geq 200 \mu$ g numerically increasing $\mathrm{FEV}_{1}$ vs baseline from 24 to $36 \mathrm{~h}$ post-dose. The change from baseline in peak $\mathrm{FEV}_{1}$ was increased by all doses of navafenterol, ranging from 0.513 to $0.870 \mathrm{~L}$ (Fig. 3 and e-Table 2). Other secondary PD endpoints, including the change from baseline in trough forced vital capacity and post-dose normalised $\mathrm{FEV}_{1} \mathrm{AUC}_{0-6}, \mathrm{AUC}_{0-12}, \mathrm{AUC}_{12-24}$, and $\mathrm{AUC}_{0-24}$ are reported in e-Table 2.

\section{Pharmacokinetics}

Following single inhalation, navafenterol was rapidly absorbed (median $t_{\max }$ values of $0.86-1.49 \mathrm{~h}$; e-Table 3). $\mathrm{C}_{\max }$ and $\mathrm{AUC}_{0_{-\infty}}$ increased dose proportionally across the dose range, according to the statistical analysis. After reaching $C_{\max }$, plasma concentrations declined in an apparent biphasic manner (Fig. 4), with mean $t_{1 / 2 \lambda z}$ ranging from 15.96 to $23.10 \mathrm{~h}$ with navafenterol doses $\geq 200 \mu \mathrm{g}$. Across all doses $\mathrm{fe}_{0-36 \mathrm{~h}}$ was very low, with $<0.4 \%$ excreted unchanged in urine. Renal clearance was consistently low, with mean values of $0.7-1.1 \mathrm{~L} / \mathrm{h}$.

The metabolite LAS191861 was rapidly formed following inhalation of navafenterol (median $t_{\max } 0.99-3.00 \mathrm{~h}$ ). Mean 


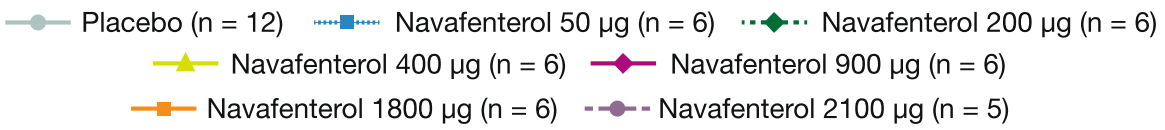

A

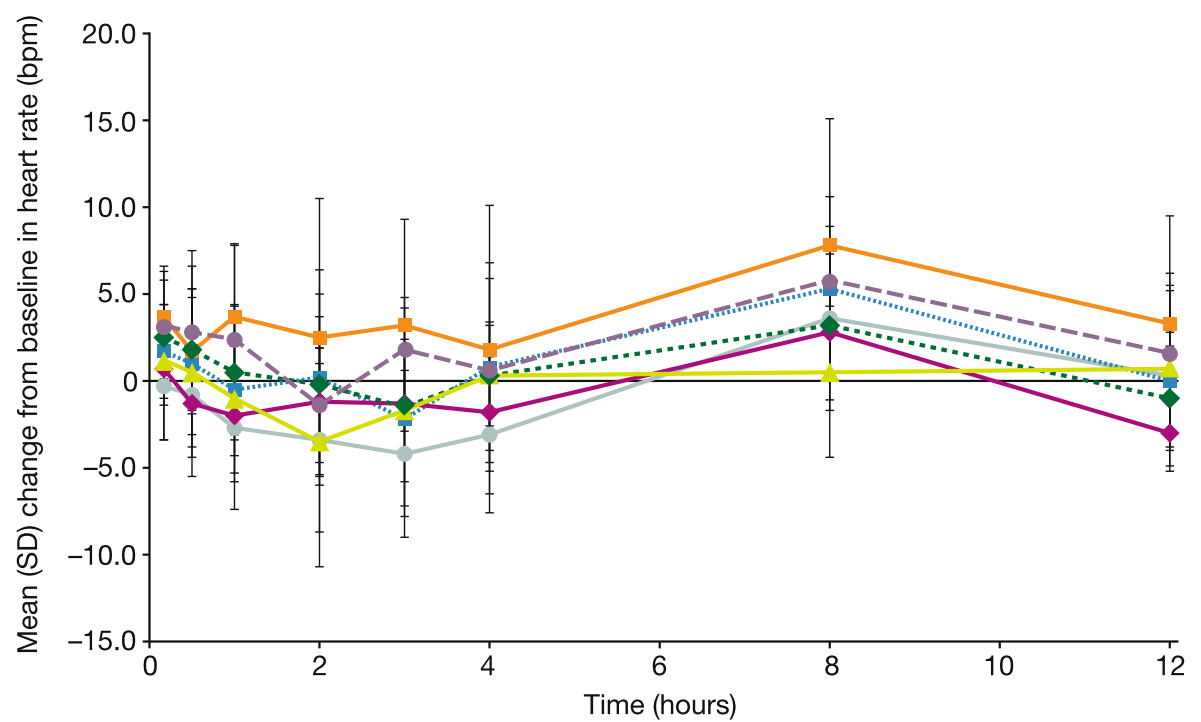

B

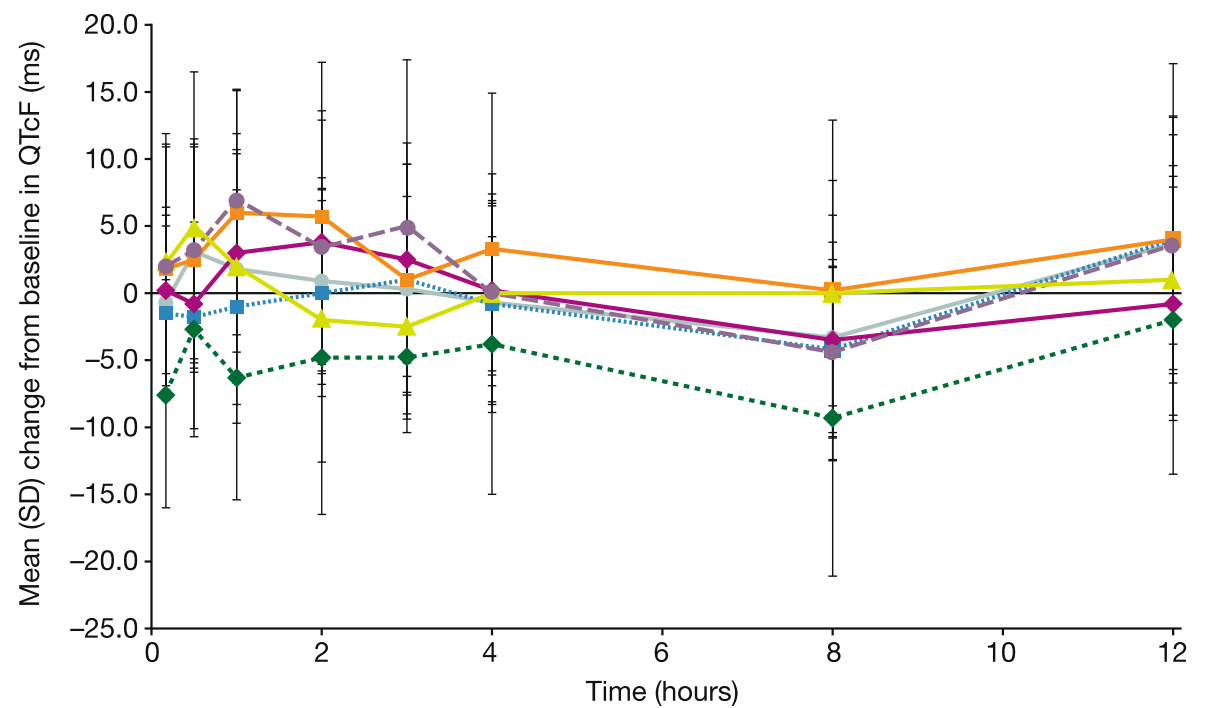

Fig. 2 Mean (SD) change from baseline in (a) heart rate and (b) QTcF at each timepoint over $12 \mathrm{~h}$ post-dose (safety population). bpm = beats per minute; QTCF = QT interval corrected for heart rate using the Fridericia formula; SD = standard deviation

metabolite to parent ratios based on $\mathrm{AUC}_{0-\infty}$ ranged from approximately 0.12 to 0.24 , independent of dose.

\section{Discussion}

In this study of patients with mild asthma, navafenterol had a rapid onset of action, with improvements in bronchodilation vs baseline observed at $5 \mathrm{~min}$ post-dose. At doses of $400-2100 \mu \mathrm{g}$ navafenterol demonstrated improvements from baseline in trough $\mathrm{FEV}_{1}$ that were statistically superior to placebo. A dose-ordered increase was observed for the changes from baseline in trough $\mathrm{FEV}_{1}$. After peak $\mathrm{FEV}_{1}$ was reached, the bronchodilatory effect gradually declined but was still sustained until the end of the observation period at $36 \mathrm{~h}$ post-dose.

The PK profile of navafenterol in plasma showed rapid absorption and dose-proportional exposure for navafenterol. Though mean $t_{1 / 2 \lambda z}$ estimates were generally consistent across doses of navafenterol, these values were 

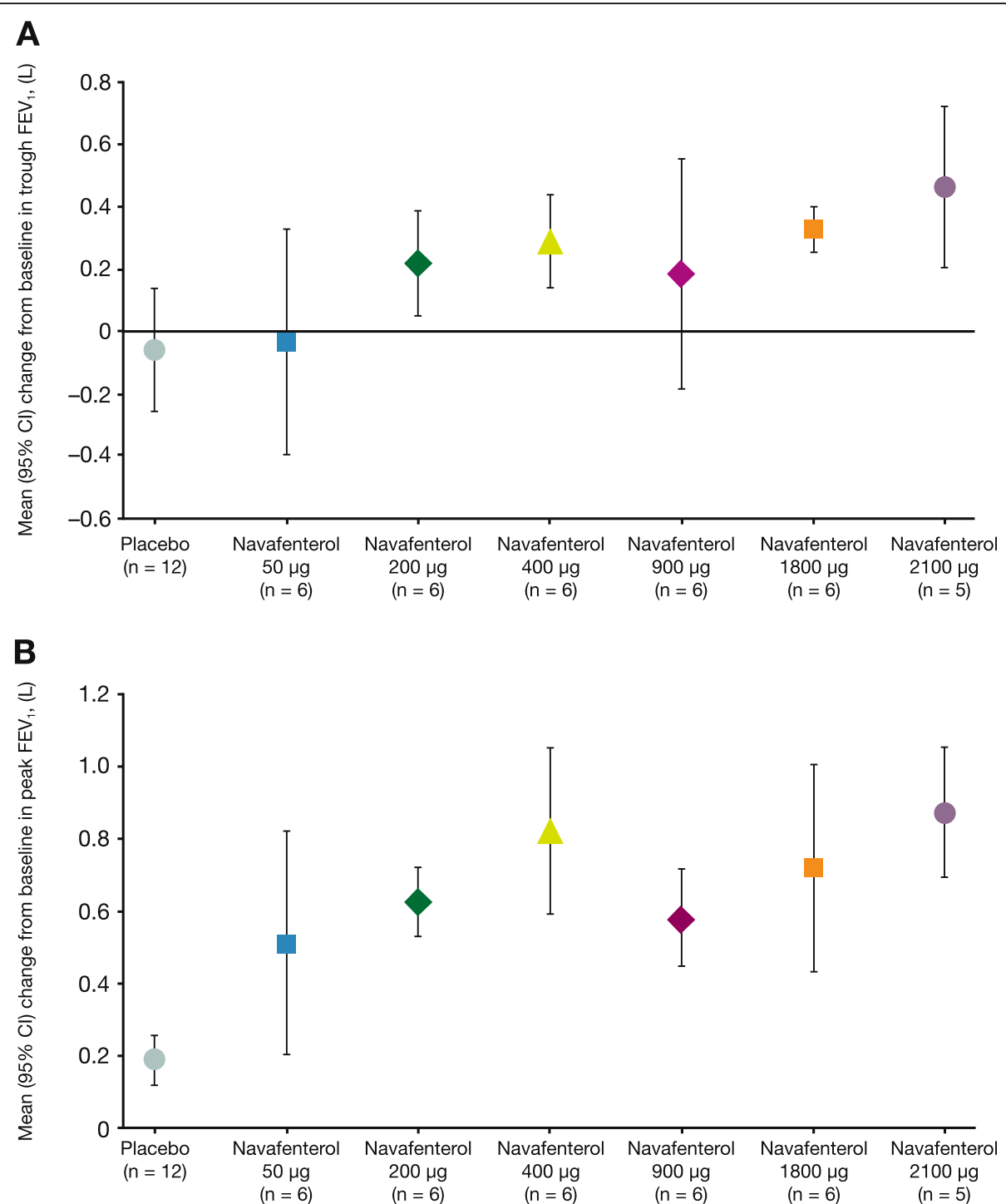

Fig. 3 Mean $(95 \% \mathrm{Cl})$ change from baseline in $\mathbf{a})$ trough and $\mathbf{b})$ peak $\mathrm{FEV}_{1}$ (per protocol population). $\mathrm{Cl}=\mathrm{confidence} \mathrm{interval;} \mathrm{FEV}_{1}=\mathrm{forced}$ expiratory volume in $1 \mathrm{~s}$

generally calculated over a period of less than three times the resultant half-life for all dose levels, which may impact the robustness of the values. A very low fraction of the dose was excreted unchanged in the urine, and low renal clearance values were suggestive of passive filtration mechanisms.

Navafenterol at doses of 50-2100 $\mu \mathrm{g}$ was generally well tolerated. No stopping criteria were reached during the study and no safety concerns were identified. Dosing remained below pre-identified maximum human exposure limits and the maximum tolerated dose was not reached.

No TEAEs were fatal, serious, severe, or led to discontinuation, and the proportion of patients reporting TEAEs was similar across treatment groups and dose levels. No TEAEs were related to laboratory findings, and no clinically significant findings were reported for clinical laboratory parameters. No prominent adrenergic symptoms were observed, and there was no indication of any cardiovascular effects, clinically relevant differences in blood pressure, or treatment-related hyperglycaemia or hypokalaemia.

Taken together, the safety and PD findings of this first-in-human study of navafenterol support the oncedaily dosing of navafenterol as an inhaled bronchodilator and warrant further clinical investigation. However, the conclusions that can be drawn from this study are limited by the small sample size and the choice of treatment population. Though this was considered to be the most sensitive population to demonstrate early signs of potential efficacy without compromising patient safety, it is not representative of the intended target population. 


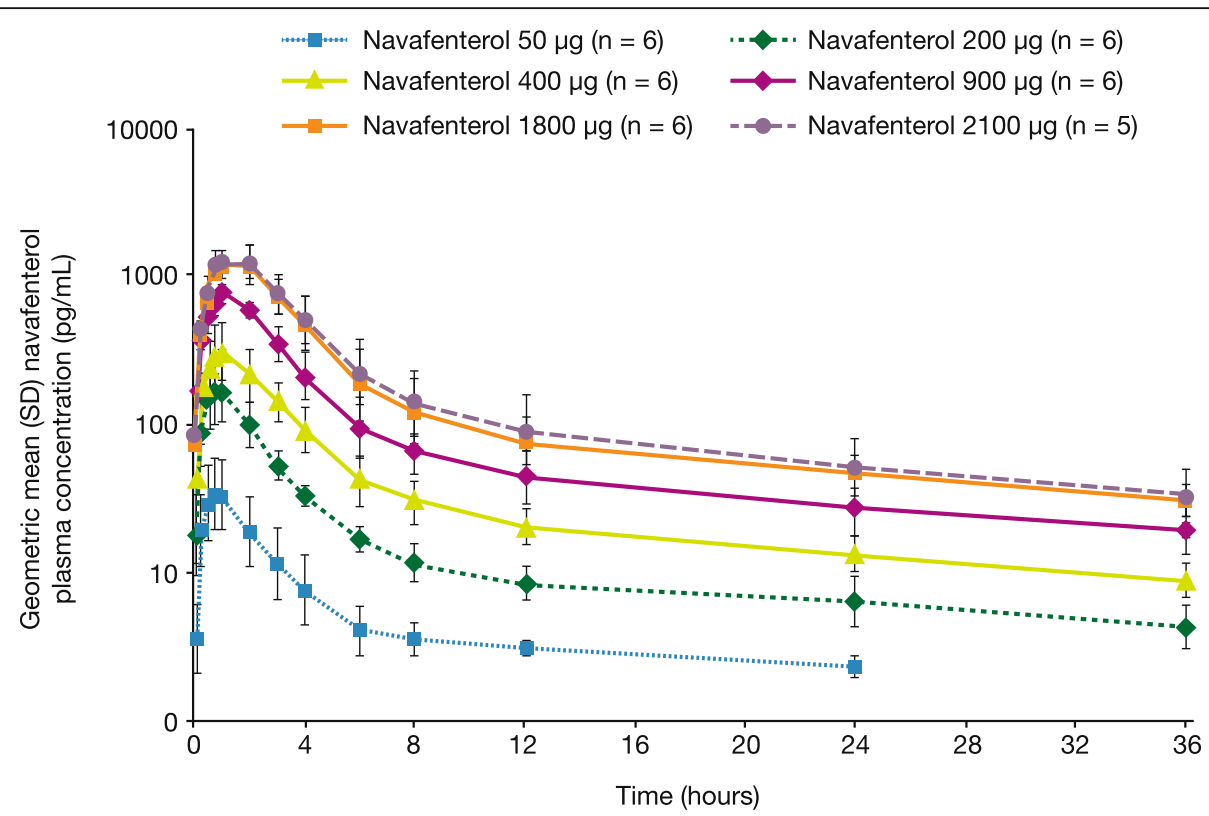

Fig. 4 Geometric mean (SD) navafenterol plasma concentration at each timepoint over $36 \mathrm{~h}$ post-dose (pharmacokinetics population). Data are shown on a semi-logarithmic scale. For error bars, the geometric mean SD is displayed as exponential (arithmetic mean of the natural logtransformed variable \pm arithmetic SD of the natural log-transformed variable). SD = standard deviation

Currently, navafenterol is being developed for use in COPD. Further studies would be required to confirm the efficacy of navafenterol in patients with COPD and in patients with severe asthma in combination with an ICS and/or another anti-inflammatory agent. With its rapid onset of action and good safety profile, it is possible that navafenterol could eventually be used as an add-on reliever medication, on a similar symptomdriven, as-needed (prn) basis to the LABA formoterol, for patients with obstructive airways disease [13]. Currently, short-acting $\beta_{2}$-agonists (SABA), short-acting muscarinic antagonists (SAMA), formoterol and ICS/ formoterol combinations are licensed for this form of use in patients with asthma [14].

\section{Conclusions}

In the first administration of navafenterol in humans, no safety concerns were raised and navafenterol 50-2100 $\mu \mathrm{g}$ was generally well tolerated, with significant and rapidonset bronchodilation (within $5 \mathrm{~min}$ post-dose), which was sustained over $36 \mathrm{~h}$. Whilst these findings are limited by the size of the study, they support further investigations of navafenterol as a dual-action inhaled bronchodilator.

\section{Supplementary information}

Supplementary information accompanies this paper at https://doi.org/10. 1186/s12931-020-01470-5.

Additional file 1 e-Appendix 1. Methods. E-Table 1. Safety Assessments. E-Table 2. Secondary Pharmacodynamic Endpoints.
E-Table 3. PK Parameters for navafenterol. e-Figure 1. The chemical structure of navafenterol. e-Figure 2. Mean (SD) change from baseline in (A) serum glucose and (B) serum potassium over $24 \mathrm{~h}$ post-dose. e-Figure 3. Mean $(95 \% \mathrm{Cl})$ change from baseline in $\mathrm{FEV}_{1}$ at each timepoint over $36 \mathrm{~h}$ post-dose.

\section{Abbreviations}

AE: Adverse event; $\mathrm{AUCO}-\infty$ : Area under the concentration-time curve from time zero extrapolated to infinity; AUCO-6: Area under the curve from 0 to 6 $\mathrm{h}$; AUCO-12: Area under the curve from 0 to $12 \mathrm{~h}$; AUC0-24: Area under the curve from 0 to $24 \mathrm{~h}$; AUC12-24: Area under the curve from 12 to $24 \mathrm{~h}$; Cl : Confidence interval; Cmax: Maximum concentration; COPD: Chronic obstructive pulmonary disease; ECG: Electrocardiogram; fe0-36 h: Fraction of the dose excreted unchanged into urine from 0 to $36 \mathrm{~h}$; FEV1: Forced expiratory volume in $1 \mathrm{~s}$; ICS: Inhaled corticosteroid; LABA: Long-acting $\beta 2$ adrenoceptor agonist; LAMA: Long-acting muscarinic receptor antagonist; MABA: Muscarinic receptor antagonist and $\beta 2$ adrenoceptor agonist; PD: Pharmacodynamics; PK: Pharmacokinetic; prn: pro re nata (as needed); QTCF: QT interval corrected for heart rate using the Fridericia formula; $t^{1} / 2 \lambda z$ : Terminal half-life; TEAE: treatment-emergent adverse event; tmax: Time to reach maximum concentration

\section{Acknowledgements}

The authors would like to thank the patients and their families, as well as the investigators and site staff who participated in this study.

\section{Prior presentation of data}

This study was previously presented at the European Respiratory Society Congress, Milan, Italy (September 9-13, 2017).

\section{Role of the sponsor}

Sponsorship for this study and article processing charges were funded by AstraZeneca. Current and former employees (EJ, CA, UW-H, BS, CV, HP, MJB, $A A$, and IP) of AstraZeneca were involved in various aspects of the conception and design of the study, acquisition of data and analysis and interpretation of data, and input into manuscript development. All authors had full access to all of the data in this study and take complete responsibility for the integrity of the data and accuracy of the data analysis. The 
corresponding author had final responsibility for the decision to submit the manuscript for publication. The sponsor did not place any restriction on authors about the statements made in the final article. The sponsor reviewed the publication to ensure medical and scientific accuracy and protection of intellectual property

\section{About this supplement}

This article has been published as part of Respiratory Research, Volume 21 Supplement 1, 2020: Results from the Phase I study programme for navafenterol (AZD8871), a novel inhaled dual pharmacology bronchodilator (MABA). The full contents of the supplement are available at https:// respiratoryresearch.biomedcentral.com/articles/supplements/volume-21 supplement-1.

\section{Authors' contributions}

EJ, CA, MA, UW-H, BS, CV, HP, MJB, and AA were involved in study design, data analysis and manuscript preparation. IP was involved in data analysis and manuscript preparation. All named authors meet the International Committee of Medical Journal Editors criteria for authorship for this manuscript, take responsibility for the integrity of the work as a whole, and have given final approval to the version to be published. EJ takes responsibility for (is the guarantor of the content of the manuscript, including the data and analysis.

\section{Funding}

This study was funded by AstraZeneca. navafenterol is an investigational product with no approved indication. Article processing charges were funded by AstraZeneca. Medical writing support, under the direction of the authors, was provided by Lauren MCNally, MSci, of CMC CONNECT, a division of Complete Medical Communications Ltd., Glasgow, UK, funded by AstraZeneca in accordance with Good Publication Practice (GPP3) guidelines [15].

\section{Availability of data and materials}

Data underlying the findings described in this manuscript may be obtained in accordance with AstraZeneca's data sharing policy described at https:// astrazenecagrouptrials.pharmacm.com/ST/Submission/Disclosure.

\section{Ethics approval and consent to participate}

The study protocol and consent form were reviewed and approved by an Independent Ethics Committee (NRES Committee - Cambridgeshire and Hertfordshire, Health Research Authority, Nottingham, UK; Reference No 15/ EE/0329) and the study was performed in accordance with the Declaration of Helskini, the International Conference on Harmonisation/Good Clinical Practice and the AstraZeneca bioethics policy. All patients provided written informed consent before taking part in the study.

\section{Consent for publication}

Not applicable.

\section{Competing interests}

EJ, CA, UW-H, BS, and IP are employees of AstraZeneca and may own stock or stock options. MA is an employee of PAREXEL. AstraZeneca contracted PAREXEL for the conduct of this study. CV, HP, MJB, and AA were employees of AstraZeneca at the time the study was conducted. CV is a current employee of PAREXEL. HP is a current employee of Allergy Therapeutics, MJB is a current employee of InsudPharma, and AA is a current employee of Eloxx Pharmaceuticals.

\section{Author details}

${ }^{1}$ Clinical Pharmacology and Quantitative Pharmacology, Clinical Pharmacology \& Safety Sciences, R\&D, AstraZeneca, 08020 Barcelona, Spain. ${ }^{2}$ Research and Early Development, Respiratory, Inflammation and Autoimmune, BioPharmaceuticals R\&D, AstraZeneca, Barcelona, Spain. ${ }^{3}$ Early Phase Clinical Unit, PAREXEL International GmbH, Harrow, UK. ${ }^{4}$ Clinical Pharmacology and Quantitative Pharmacology, Clinical Pharmacology \& Safety Sciences, R\&D, AstraZeneca, Gothenburg, Sweden. ${ }^{5}$ Biometrics and Information Sciences, Late-Stage Development, BioPharmaceuticals R\&D, AstraZeneca, Barcelona, Spain. ${ }^{6}$ Late-Stage Development, BioPharmaceuticals R\&D, AstraZeneca, Barcelona, Spain. ${ }^{7}$ Patient Safety, Chief Medical Office, R\&D, AstraZeneca, Barcelona, Spain. ${ }^{8}$ Research and Early Development, Respiratory, Inflammation and Autoimmune, BioPharmaceuticals R\&D, AstraZeneca, Gothenburg, Sweden.
Received: 12 June 2020 Accepted: 24 July 2020

Published: 9 September 2020

\section{References}

1. Global Initiative for Asthma. 2018 GINA Report, Global Strategy For Asthma Management and Prevention. 2018. http://ginasthma.org/2018-gina-reportglobal-strategy-for-asthma-management-and-prevention/. Accessed 04/20/ 2018.

2. Kew KM, Dahri K. Long-acting muscarinic antagonists (LAMA) added to combination long-acting beta2-agonists and inhaled corticosteroids (LABA) ICS) versus LABA/ICS for adults with asthma. Cochrane Database Syst Rev. 2016;1:CD011721.

3. Kerstjens HA, Engel M, Dahl R, et al. Tiotropium in asthma poorly controlled with standard combination therapy. N Engl J Med. 2012;367(13):1198-207.

4. Ohta $\mathrm{K}$, Ichinose M, Tohda $\mathrm{Y}$, et al. Long-term once-daily tiotropium Respimat ${ }^{\top}$ is well tolerated and maintains efficacy over 52 weeks in patients with symptomatic asthma in Japan: a randomised, placebo-controlled study. PLoS One. 2015;10(4):e0124109.

5. Cazzola M, Lopez-Campos JL, Puente-Maestu L. The MABA approach: a new option to improve bronchodilator therapy. Eur Respir J. 2013;42(4):885-7.

6. de Miguel-Díez J, Jiménez-García R. Considerations for new dual-acting bronchodilator treatments for chronic obstructive pulmonary disease. Expert Opin Investig Drugs. 2014;23(4):453-6.

7. Bourbeau J, Bartlett SJ. Patient adherence in COPD. Thorax. 2008;63(9):8318.

8. Cazzola M, Matera MG. Novel long-acting bronchodilators for COPD and asthma. Br J Pharmacol. 2008;155(3):291-9.

9. Agh T, Inotai A, Meszaros A. Factors associated with medication adherence in patients with chronic obstructive pulmonary disease. Respiration. 2011; 82(4):328-34.

10. Hughes $A D$, Jones $L H$. Dual-pharmacology muscarinic antagonist and $\beta 2$ agonist molecules for the treatment of chronic obstructive pulmonary disease. Future Med Chem. 2011;3(13):1585-605.

11. Cazzola M, Page CP, Calzetta L, Matera MG. Pharmacology and therapeutics of bronchodilators. Pharmacol Rev. 2012;64(3):450-504.

12. Singh $D$, Astbury $C$, Jimenez $L$, et al. A randomized placebo and active controlled trial of AZD8871 a novel dual acting bronchodilator in COPD patients. Eur Respir J. 2017;50(Suppl. 61):PA1798.

13. Oxis Turbohaler 12, inhalation powder. Datapharm Ltd; 2020. https://www. medicines.org.uk/emc/product/878/smpc. Accessed 12 Feb 2020.

14. Global Initiative for Asthma. 2020 GINA Report, Global Strategy for Asthma Management and Prevention. Fontana, WI, USA, 2020. Available at https:/ ginasthma.org/gina-reports/. Accessed July 2020.

15. Battisti WP, Wager E, Baltzer $L$, et al. Good publication practice for communicating company-sponsored medical research: GPP3. Ann Intern Med. 2015;163(6):461-4.

\section{Publisher's Note}

Springer Nature remains neutral with regard to jurisdictional claims in published maps and institutional affiliations.

\section{Ready to submit your research? Choose BMC and benefit from:}

- fast, convenient online submission

- thorough peer review by experienced researchers in your field

- rapid publication on acceptance

- support for research data, including large and complex data types

- gold Open Access which fosters wider collaboration and increased citations

- maximum visibility for your research: over $100 \mathrm{M}$ website views per year

At BMC, research is always in progress.

Learn more biomedcentral.com/submission 